\title{
The necessity for spirometry in the primary care management of COPD
}

\author{
Niels Chavannes*
}

\author{
Department of General Practice, Caphri Research Institute, Maastricht University, 6229 HA Maastricht, \\ The Netherlands
}

\author{
KEYWORDS \\ Spirometry; \\ COPD; \\ Primary care; \\ Chronic obstructive \\ pulmonary disease
} Summary Implementation of spirometry in the primary care setting is controversial.
Spirometry allows a unique non-invasive look into the functioning of the lungs, which
can be both medically informative and of practical value. Respiratory complaints are
among the most prevalent in primary care, while smoking rates remain globally high,
illustrating the need for proper tools to investigate the possible causes of chronic
pulmonary symptoms. Smoking cessation programs and disease management programs
are the preferred treatment strategies for COPD; these rely on a valid spirometric
diagnosis, as promoted by international COPD guidelines. In addition, involving the
patient in treatment plans and explaining the detrimental effects of smoking can be
greatly facilitated by the visual impact of a flow-volume curve, have promoted the use
of spirometry. While there are difficulties in implementation of spirometry in primary
care. Provided that quality standards of performance and training are sufficiently met,
evidence suggests that spirometry is a valid, feasible and interpretable diagnostic
tool in a primary care setting. COPD is a growing problem for society, which should
not be underestimated, and with sufficient funding, adequate training and motivated
healthcare workers, there is no goodreason why spirometric testing cannot be widely
implemented.
@ 2003 General Practice Airways Group. Published by Elsevier Ltd. All rights reserved.
Over the past few years, increasing attention has been paid to the detection and treatment of chronic obstructive pulmonary disease (COPD) in primary care, in part caused by the worldwide increase in burden and mortality [1]. In contrast with other major diseases, the prevalence of COPD will continue to rise, predominantly caused by an increase in the numbers of female patients with COPD [2]. Early diagnosis of COPD is important, since smoking cessation can reduce the rate of progression to severe disease [3], which benefits each patient and every practice. There are, however, both patient- and healthcare provider-related factors which hamper

\footnotetext{
*Tel.: +31-43-3882315; fax: +31-43-3619344

E-mail address: niels.chavannes@hag.unimaas.nl (N. Chavannes).
}

this early detection [4], in particular underreporting of complaints and lack of active detection.

Spirometry is being increasingly implemented throughout primary care in Western Europe, and in some countries is now being used in the majority of practices $[5,6]$. GPs seem to appreciate this relatively new tool highly [7], as it generates diagnostic information previously unattainable in primary care. It provides a comprehensive overview of airflow and lung capacity, and with high quality measurement, permits an accurate and reliable diagnosis of obstructive airways disease and the degree of reversibility. A recent study has shown for the first time that performing simple spirometric tests in the primary care setting produces results at least as good as those of pulmonary function laboratories [8]. Recognizing patterns of obstruction, 
[14] van Schayck CP, Loozen JMC, Wagena E, Akkermans RP, Wesseling GJ. Detecting patients at a high risk of developing chronic obstructive pulmonary disease in general practice: cross sectional case finding study. BMJ 2002;324:1370.

[15] Jackson H, Hubbard R. Detecting chronic obstructive pulmonary disease using peak flow rate: cross sectional survey. BMJ 2003;327:653-4.

[16] White PT, Cajeat E, Fleming T, Nolan D, Gray B. The relationship between peak expiratory flow rate (PEFR) and forced expiratory volume in the first second $\left(\mathrm{FEV}_{1}\right)$ at low levels of $\mathrm{FEV}_{1}$. Implications for the assessment of COPD (chronic obstructive pulmonary disease) in primary care. Eur Respir J 2002;20(Suppl 38):397s.

[17] Mannino DM, Ford ES, Redd SC. Obstructive and restrictive lung disease and markers of inflammation: data from the Third National Health and Nutrition Examination. Am J Med 2003;114:758-62.

Available online at www.sciencedirect.com

science $\boldsymbol{d}$ direct. 


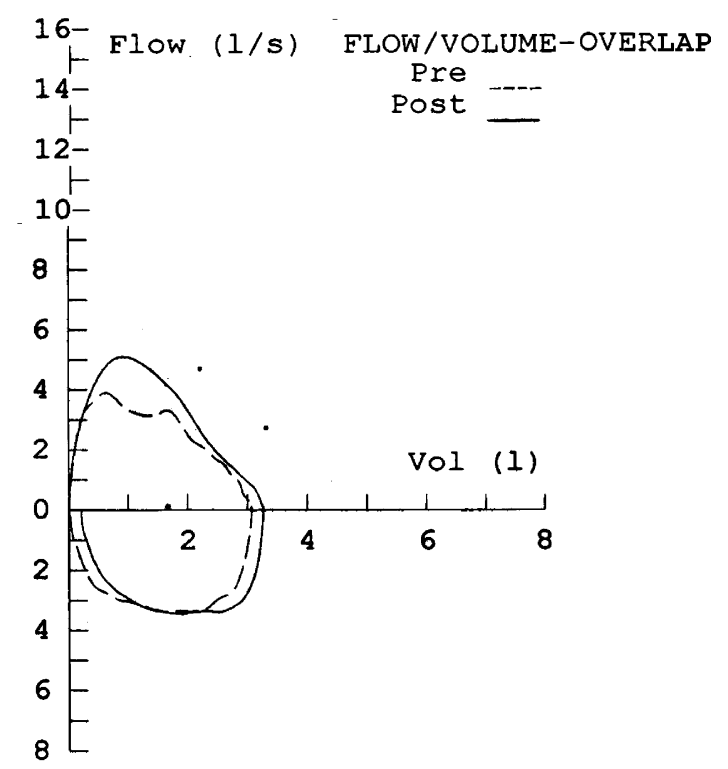

Figure 1 A tongue-indentation in the pre-bronchodilator curve.

physiological curves and being able to assess the quality of the spirometric procedure, is peasible and adds to the quality of general practice [9]. Most importantly, it has proved to be a helpful tool in convincing patients to stop smoking [10], with the spirometric diagnosis providing the motivation to quit in the long-term [11].

A few flow-volume curves from patients in my own practice illustrate the above issues. Fig. 1 illustrates the flow-volume curve from a patient who 'tongued' the mouthpiece whilst performing the spirometric manoeuvre, causing an indented pattern easily recognized on the flow-volume curve. If one was relying only on peak expiratory flow (PEF) measurement, this poor quality manoeuvre would have suggested PEF-reversibility. Fig. 2 represents a typical flow-volume loop from a patient with moderately severe COPD, but with a relatively preserved PEF measurement as is often the case. If relying on PEF measurement alone, the severity of disease would have been grossly underestimated. Fig. 3 is a flow-volume loop suggestive of restrictive lung disease; this 52-year-old patient complained of progressively decreased exercise tolerance without ever smoking. The forced vital capacity (FVC) and forced expiratory volume in $1 \mathrm{~s}\left(\mathrm{FEV}_{1}\right)$ are both reduced at 62.8 and $67.3 \%$ predicted, respectively, but the $\mathrm{FEV}_{1} / \mathrm{FVC}$ ratio is normal (greater than 0.7 ) showing that this is not an obstructive curve. PEF is normal and would not have contributed a great deal to the diagnosis. The differential diagnosis includes sarcoidosis and lung fibrosis, both serious conditions, and this patient is currently under investigation at the pulmonary department.

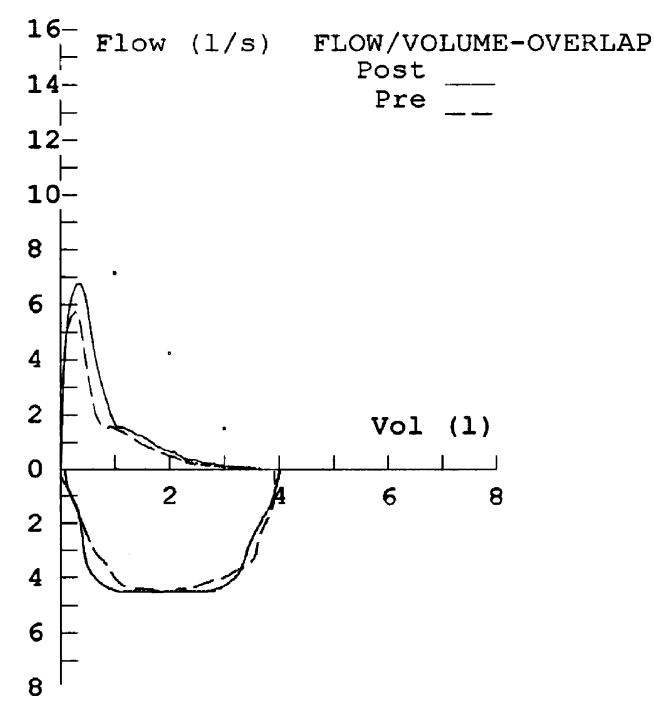

Figure 2 Obstructive pattern with peak expiratory flow relatively preserved.

In disease management programs for COPD, spirometry plays a central role in re-confirming the diagnosis (providing further argument for smoking cessation), and in monitoring disease progression. An annual review for a COPD patient who is still smoking, would include assessment of medication adherence, body mass index (BMI), exercise tolerance and social functioning, and would incorporate measurements made during more frequent contacts with the respiratory nurse over the previous year. This generates crucial information for smoking cessation purposes, which can be directly enforced by using the results of spirometry. All these assets are potentially available within the daily practice

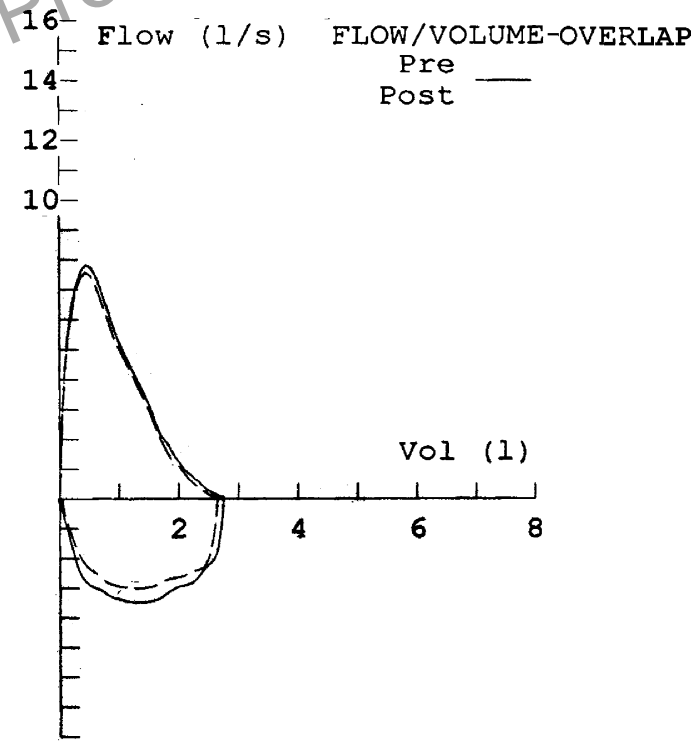

Figure 3 A restrictive pattern with normal peakflow. 
setting, provided that adequate spirometric training and quality control are maintained [8]. In several countries, reimbursement policies for performing spirometry have improved, so that it can be an economically sound part of primary care business as well.

A majority of patients prefer domiciliary over hospital care [12], leading to greater patient satisfaction [13]. Thus, spirometry in the primary care setting can be an important example of this demand-driven care.

The proportion of patients eligible for spirometry is considerable in the primary care population, since smoking rates have remained at high levels and respiratory symptoms are among the most frequently presented. It is possible to perform screening of all smokers [10], but this is likely to present a large burden on practice time and resources. Therefore, it seems more practical to use case-finding strategies to detect high-risk patients, which has been shown to increase detection rates of COPD from 18 to $48 \%$ by selecting patients on the basis of age, symptoms and smoking [14]. Recently, it has been proposed that PEF measurement instead of spirometry testing should be used to detect obstructive airways disease [15], based on secondary analyses of a large American database. In this study, although PEF testing didn't seem to miss many cases of COPD, it did lead to a positive predictive value of just $30 \%$. The question this short paper fails to answer is: what should be done with the resulting crude selection in practice?-that is, how many of these detected cases are actually asthmatic patients who may need inhaled corticosteroids?, and which ones have COPD and should be referred because of an $\mathrm{FEV}_{1}$ less than $50 \%$ of predicted? Previously, it has been demonstrated that PEF correlation with $\mathrm{FEV}_{1}$ diminishes as obstructive disease becomes more severe [16], illustrating the necessity for spirometry to distinguish between patients who are in need of referral and those who can be treated in primary care. In addition, using spirometry for COPD case-finding has been shown to produce a significant number of patients with restrictive lung disease, cases which would have been missed using PEF measurement alone [17]. Probably, all these patients still need spirometry testing, be it at a local diagnostic center or a hospital.

In conclusion, with sufficient funding, adequate training and motivated healthcare workers, there is no good reason why spirometric testing cannot be widely implemented. COPD is a growing problem for society which should not be underestimated. It was once thought appropriate to measure blood pressure by the physician using his fingertips, and the establishment of a detailed diagnosis in terms of millimeters of mercury was the task of a specialist. To measure is to know; primary care physicians should strive to be the first to know about their patients' airways disease, and should not be too humble about it.

\section{References}

[1] Pauwels RA, Buist AS, Calverley PM, Jenkins CR, Hurd SS. Gold Scientific Committee. Global strategy for the diagnosis, management, and prevention of chronic obstructive pulmonary disease. NHLBI/WHO Global Initiative for Chronic Obstructive Lung Disease (GOLD) Workshop Summary. Am J Respir Crit Care Med 2001;163:1256-76.

[2] Mannino DM, Homa DM, Akinbami LJ, Ford ES, Redd SC. Chronic obstructive pulmonary disease surveillanceUnited States, 1971-2000. Centers for Disease Control and Prevention, Surveillance Summaries. Morb Mortal Wkly Rep 2002;51:1-16.

[3] Anthonisen NR, Connett JE, Kiley JP, Altose MD, Bailey WC, Buist AS, et al. Effects of smoking intervention and the use of an inhaled anticholinergic bronchodilator on the rate of decline of $\mathrm{FEV}_{1}$. The Lung Health Study. JAMA 1994;272:1497-505.

[4] Schayck van CP, Chavannes NH. Detection of asthma and chronic obstructive pulmonary disease in primary care. Eur Respir J 2003;21(Suppl 39):16s-22s.

[5] Arne M. Spirometry in primary care: a need for standardization. Eur Respir J 2002;20(Suppl 38):414s.

[6] Bashford S, Chadwick S, Ward J, Mclntyre P, Dent R, Williams I. Identifying chronic obstructive pulmonary disease in the community-a primary care survey. Eur Respir J 2002;20(Suppl 38):413s.

[7] Donner F, Lusuardi M, De Benedetto F, Paggiaro L, Sanguinetti $M$, Poli $A$, et al. Office spirometry in asthma and COPD: role and feasibility in standard practice. Preliminary data of the "SPACE" Italian study. Eur Respir J 2003;22(Suppl 45):4395.

[8] Schermer TR, Jacobs JE, Chavannes NH, Hartman J, Folgering HT, Bottema BJ, et al. Validity of spirometric testing in a general practice population of patients with chronic obstructive pulmonary disease (COPD). Thorax 2003;58:86186.

[9] Chavannes NH, Schermer TRJ, Akkermans RP, Jacobs $\mathrm{JE}$, van de Graaf G, Bollen R, et al. Interpretation of spirometry in general practice: pattern recognition and decision-making. Eur Respir J 2002;20(Suppl 38):414s.

[10] Gorecka D, Bednarek M, Nowinsky A, Puscinska E, GoljanGeremek A, Zielinsky J. Diagnosis of airflow limitation combined with smoking cessation advice increases stop-smoking rate. Chest 2003;123:1916-23.

[11] Czajkowska-Malinowska M, Gorecka D, Zielinski J. Effects of repeated spirometries and anti-smoking counselling on smoking cessation rate. Eur Respir J 2002;20(Suppl 38):134s.

[12] Ojoo JC, Moon T, McGlone S, Martin K, Gardiner ED, Greenstone MA, et al. Patients' and carers' preferences in two models of care for acute exacerbations of COPD: results of a randomised controlled trial. Thorax 2002;57: 167-9.

[13] Wilson A, Wynn A, Parker H. Patient and carer satisfaction with "hospital at home"': quantitative and qualitative results from a randomised controlled trial. Br J Gen Pract 2002;52:9-13. 